\title{
Teaching sustainable urbanism in the higher school: theoretical and methodological approaches
}

\author{
Vitalii Mishchenko ${ }^{1, *}$, Natalya Bykovskaya $^{2}$, and Tatiana Aleksashina ${ }^{3}$ \\ ${ }^{1}$ Altai State University, 656049, Lenin ave., 61, Barnaul, Russia \\ ${ }^{2}$ Russian State Agricultural University, 143907, Entuziastov shosse, 50, Balashikha, Russia \\ ${ }^{3}$ Russian University of Transport, 127055, Minayevsky pereulok, 2, Moscow, Russia
}

\begin{abstract}
The article deals with the growing problem of training personnel for the new economy and social life in Russia, focused on achieving sustainable development of urban areas. We consider the main directions of training future specialists in the field of urban development, relying on the Russian and world experiences.
\end{abstract}

\section{Introduction}

We are witnessing global processes in the development of new types of industries occurring in the growth of the population, scientific and technological progress, the expansion of the extraction of natural resources, the deteriorating environment, etc. As a response to the growing opportunities for human progress and, consequently, the increasing pressure on the environment, the concept of sustainable development was adopted at the UN level, that is, it was supported internationally. This concept emphasizes the importance of rational and responsible use of natural resources. Satisfaction of the current needs of mankind and the detrimental impact of the results of its activities should not have a negative impact on the development of future generations.

It is worth noting that many states are focused on the long-term territorial development of their rural areas and cities in particular. For example, the Ministry of the Russian Federation is implementing a program of sustainable regional development at the federal level. Moreover, many municipalities and city administrations also have sustainable development strategies. Nevertheless, we note the insufficient number of personnel who could professionally adjust these programs, support them, and implement them to the proper extent. The importance of the concept of sustainable development is not to be questioned, but the human resource, in our opinion, leaves much to be desired. This article is designed to consider the issue of teaching sustainable urbanism in modern higher education in Russia, to propose the structure of this program, and to identify the main difficulties in teaching sustainable urbanism in Russian universities.

\footnotetext{
* Corresponding author: m.vitaly53@mail.ru
} 


\section{Achieving a perfect program structure}

The educational program on sustainable urbanism should meet, in our opinion, several critical challenges in the area of (a) theoretical training in sustainable development, (b) highly specialized practical training in sustainable urban development, (c) understanding the interconnectedness of economic, social, technical, and environmental factors of sustainable development of urban areas.

Students attending the program on sustainable urbanism should acquire methodological, methodological, and practical skills in analyzing the factors and specifics of the development of cities in Russia and the world within the framework of the sustainable development paradigm, and they should obtain general and special knowledge about the features and problems of sustainable urban development [3]. In addition, such a course, and we fully agree with [3], should provide the following opportunities: (a) to give a general idea of the sustainable development of cities; (b) to provide basic concepts of the social and economic development of cities; (c) to give an idea of the experience of the territorial planning of sustainable development of cities and their agglomerations; (d) to introduce the experience of the applied policies and mechanisms for sustainable urban development; (e) to give an idea of the foreign and domestic experience of organizing the management of sustainable development of the city.

First, the training of specialists in the field of sustainable urbanism should be based on excellent theoretical training. Bachelors and Masters should form an understanding of the general issues of sustainable development as a modern concept of global, national, and regional governance. The concept of sustainable development of the city should necessarily be considered within the general concept of sustainable development of the territories, focusing on the city's place in the territorial organization of sustainable development.

Second, different aspects of the notion of "sustainable urbanism" should be considered, including the integration of social, economic, and environmental factors that are, in turn, interrelated. There are a large number of risks associated with the social and economic development of society and the development of cities. For example, one of the most striking examples of such development is the situation with single-industry towns in the Russian Federation. As a rule, single-industry have the following characteristics: (a) the presence in the city of an enterprise or complex of enterprises that belong to the same sector of the economy, which makes them very unstable in the event of a fall in production in this sector (Fig. 1); (b) the high dependence of the city budget on tax revenues from a single enterprise (the city budget has a serious deficit when revenues fall); (c) the workers' orientation to a particular production (which does not allow the effective development of other sectors of the economy due to a lack of qualified labor) [8]. Such cities face many problems in socio-economic development during a crisis in any branch of the economy on which they heavily depend [9]. Solving the problems of single-industry towns is possible when adopting the concept of sustainable urban development $[8,9]$.

In addition, students should understand the existence of environmental restrictions on the socio-economic development of cities. Many countries in the developing world want to have the same economy as the countries of the Organization for Economic Cooperation and Development (OECD) have, but they are experiencing a great environmental burden [4]. At the moment, we do not see any restrictions on their growth, and therefore, there are no restrictions on the growth of environmental pollution in their territories. Many of these countries do not want to impose environmental restrictions on their economic growth, fearing its inevitable slowdown, which is a threat to their social and political stability. However, this behavior does not fit into the category of sustainable development. Despite achieving impressive growth of their national economy, such countries will be forced to suffer from environmental pollution in the long term. Thus, the presence of environmental 
limits on harmful production and the organization of proper environmental protection should be in the presence to ensure sustainable territorial development, as far as cities are concerned [5].

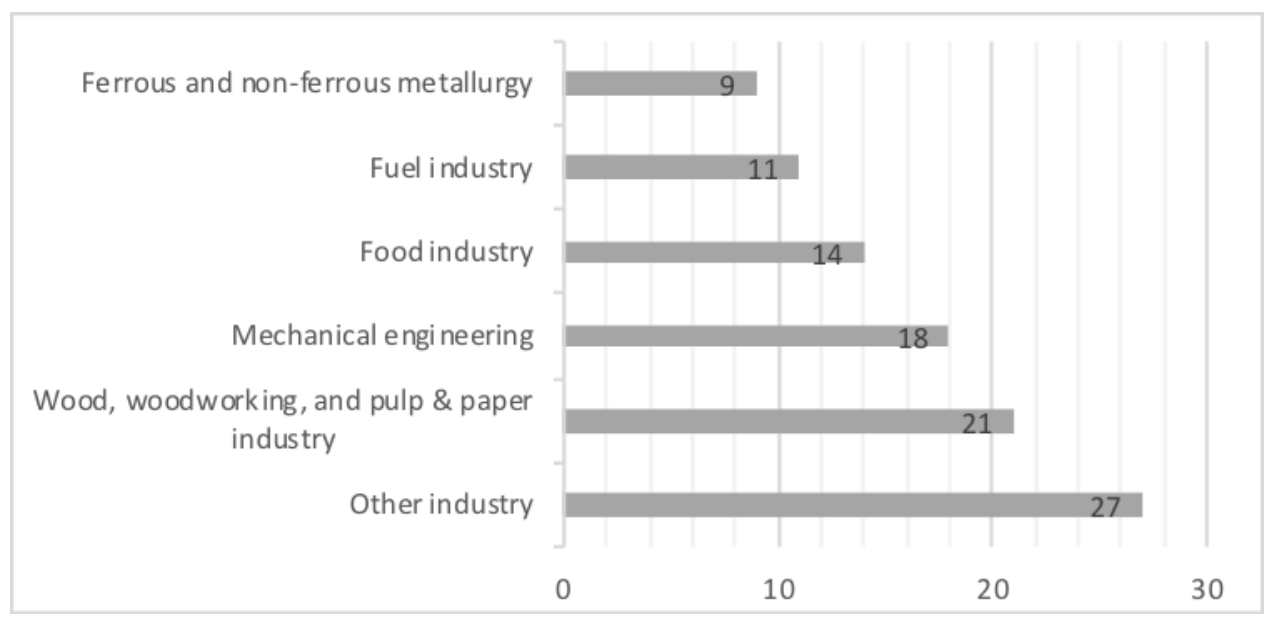

Fig. 1. Specialization of single-industry towns in Russia, \% (2016).

We also believe that students should form a voluminous and broad understanding of the economy as part of the ecosystem (Fig. 2) in order to be able to fully grasp the concept of urban sustainable development [1].
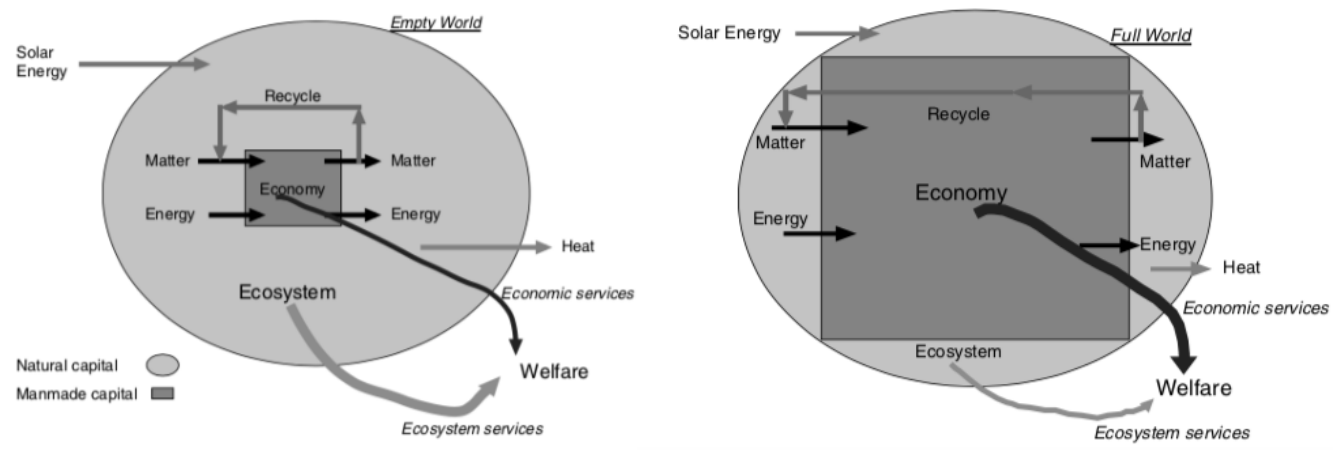

Fig. 2. A "macro" view of the macroeconomy [1].

Third, the Russian and foreign experience of sustainable development of urban areas must necessarily be considered at the bachelor's and master's programs on sustainable development. In particular, we believe that this is necessary to pay attention to the territorial planning of sustainable urban development by city authorities and private construction organizations of Russia, the European Union, the United States, Canada, and China. In addition, students should have an idea of what powers the central and city authorities have in different countries of the world, as well as how the processes of sustainable development of urban areas in different parts of the power vertical are affected by the scope of powers a specific city has to implement its plans, including the amount of resources provided for planning and implementation of sustainable urban development programs.

Another very important aspect of students' education is their opportunity to get acquainted with the tools of spatial planning and their role in achieving the main goals of 
sustainable development [3]. These tools are the general regulations and technical regulations, land use and development rules, zoning and regulations for the permitted use of real estate, etc. Moreover, students should be aware of the methodology, the development procedure, and the procedure for agreeing master plans and other spatial planning documents.

Fourth, we believe that the educational program on sustainable development should also focus on (a) transformational processes aimed at intra-urban space in order to achieve urban sustainable development, including social, economic, political, and environmental aspects of such transformation processes; (b) to achieve an understanding of the impact of human activities on the urban environment [6]. For example, different economic activities of people (in industry, agriculture, transport) have a different impact on the territorial development of the city. Another important aspect of the educational program on sustainable urbanism should cover the political mechanisms for achieving sustainable development of urban areas on a national, regional, and local scale.

For example, N. Li et al. [2] provide the results of a pedagogical experiment in urban sustainability education. They note that the program on sustainable urbanism is necessary to overcome the challenges with which modern cities, their economy and ecology face. The authors believe that pedagogical efforts in this direction can significantly improve the sustainability of cities around the world, which is especially necessary for South-East Asia [2]. In particular, their research shows increasing critical competencies even in short courses on sustainable urbanism (Fig. 3).

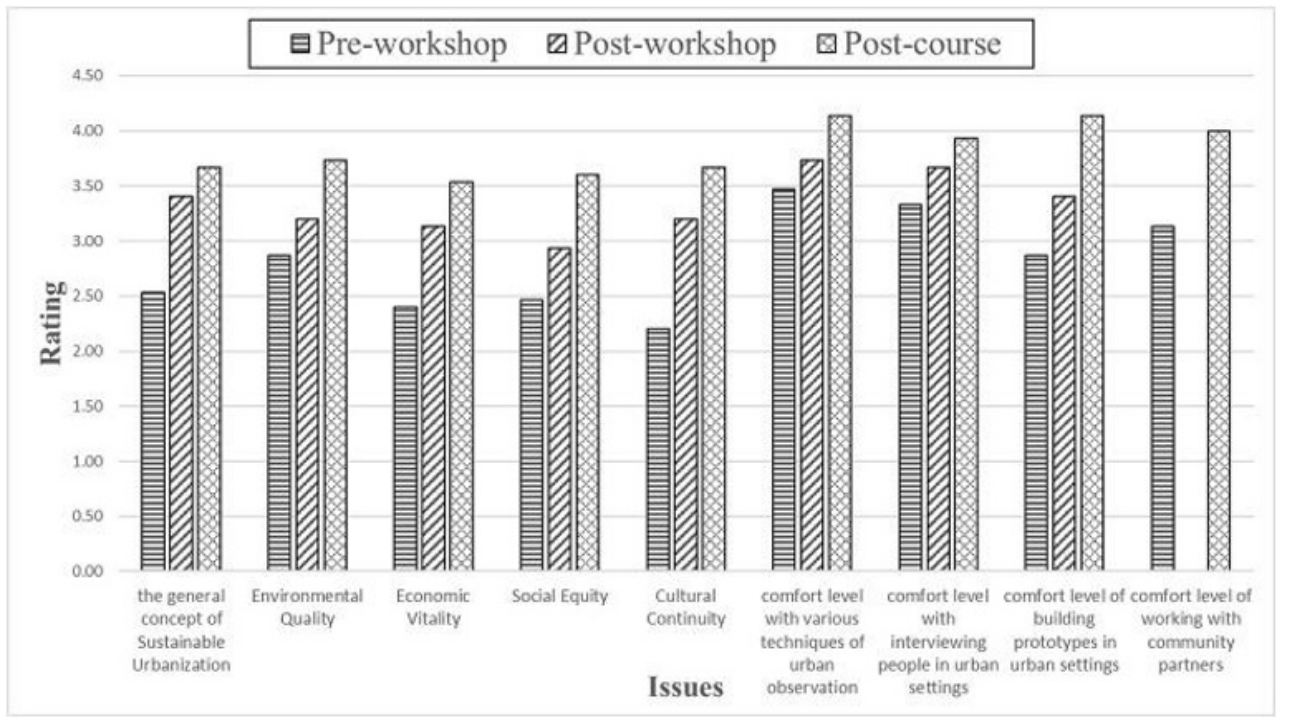

Fig. 3. Students' knowledge and comfort level rating during the teaching cycle [2].

Thus, an effective educational program to train specialists in the sustainable development of urban areas should be based on several key aspects. First, it should provide in-depth theoretical knowledge in the field of sustainable development. Second, students should receive theoretical and practical experience in the field of sustainable development of urban areas, acquiring specialization within a specific territory. Third, such an educational program should be prepared on the basis of theoretical and practical experience of both Russian and foreign government bodies, non-governmental organizations, and businesses. 


\section{Conclusion}

The concept of sustainable development is one of the leading ones in the field of modern urban development. Unfortunately, the Russian higher school produces an insufficient number of specialists in the field of sustainable urbanism, and their required number is to only grow. An educational program on sustainable urbanism can help solve a number of problems that Russia is facing at the moment. However, it should be very well organized and focused on a number of important aspects of sustainable urban development, which we outline in the article.

\section{References}

1. H. E. Daly, Ecological economics and sustainable development, selected essays of Herman Daly (Eward Elgar, Cheltenham, 2007)

2. N. Li, De. Chan, Q. Mao, K. Hsu, Z. Fu, Habitat International, 71 (2018)

3. V. P. Bityukova, A. G. Makhrovam V. E. Shuvalov, Regionalniye Issledovaniya, 6, 21 (2008)

4. A. R. Romeiro, Estudos Avabcados, 26, 74 (2012)

5. C. Davidson, BioScience, 50, 5 (2000)

6. I. S. Rampasso, R. Anholon, D. Silva, R. E. Cooper Ordoñez, O. L. G. Quelhas, W. L. Filho, L. A. Santa-Eulália, Journal of Cleaner Production, 193 (2018)

7. G. Tejedor, J. Segalàs, M. Rosas-Casals, Journal of Cleaner Production, 175 (2018)

8. D. Ku. Zemlyanskii, Regional Research of Russia, 1, 1 (2011)

9. G. Yu Boyarko, E. G. Matyugina, O. V. Pogharnitskaya, L. S. Grinkevich, Gornyi Zhurnal, 1, 7 (2017) 